Ni Wayan Manik Parwati, Idah Ayu Wulandari, Putu Ayu Ratna Darmayanti, Karateristik Dan Persepsi Ibu Balita Tentang Pemanfaatan Buku KIA Sebagai Deteksi Dini Tumbuh Kembang Balita Di Masa Adaptasi Tatanan Hidup Bru

\title{
KARAKTERISTIK DAN PERSEPSI IBU BALITA TENTANG PEMANFAATAN BUKU KIA SEBAGAI DETEKSI DINI TUMBUH KEMBANG BALITA DI MASA ADAPTASI TATANAN HIDUP BARU
}

\author{
Ni Wayan Manik Parwati ${ }^{1}$ \\ Institut Teknologi dan Kesehatan Bali \\ Corresponding author E-mail : manikparwati82@gmail.com \\ Idah Ayu Wulandari ${ }^{2}$ \\ Institut Teknologi dan Kesehatan Bali \\ Corresponding author E-mail : ayuwulandari28@gmail.com \\ Putu Ayu Ratna Darmayanti ${ }^{3}$ \\ Institut Teknologi dan Kesehatan Bali \\ Corresponding author E-mail : darmayantiratna@gmail.com
}

\begin{abstract}
ABSTRAK
Tatanan hidup baru selama pandemi COVID-19 juga berdampak pada pelayanan kesehatan untuk balita terutama dalam hal pemantauan deteksi dini tumbuh kembang balita. Pemanfaatan buku KIA sebagai deteksi dini tumbuh kembang balita menjadi hal yang harus diperhatikan. Penelitian ini bertujuan untuk mengetahui karakteristik dan persepsi ibu balita tentang pemanfaatan buku KIA. Penelitian ini merupakan penelitian analitik korelasi dengan pendekatan cross sectional. Jumlah sampel dalam penelitian ini 124 responden di kota Denpasar menggunakan analisis uji Chi Square. Hasil Penelitian menunjukkan karakteristik umur responden paling banyak umur 2630 tahun $(36,3 \%)$, jumlah anak $1(42,8 \%)$, pendidikan menengah $(52,4 \%)$ dan tidak bekerja $(33,1 \%)$. Sebagian besar responden memiliki persepsi yang positif $(77.4 \%)$ serta mampu memanfaatkan buku KIA sebagai deteksi dini tumbuh kembang balita dengan baik $(74,2 \%)$. Terdapat hubungan antara karakteritik umur $(p=0,075)$ jumlah anak $(p<0,001)$, pendidikan $(p=0,001)$ dan persepsi $(p=0,02)$ dengan pemanfaatan buku KIA, sedangkan karakteristik pekerjaan ibu tidak berhubungan dengan pemanfaatan buku KIA sebagai deteksi dini pertumbuhan dan perkembangan $(p=0,131)$. Ibu yang memiliki balita diharapkan menggunakan buku KIA dengan optimal sebagai deteksi dini tumbuh kembang balita agar kedepannya perkembangan anak tidak terhambat.
\end{abstract}

Kata Kunci : Balita, Buku KIA, Deteksi dini, Tumbuh Kembang

\begin{abstract}
The new normal era during Covid-19 pandemic has an effect to health services especially on monitoring early detection on growth and development of children under five. The use of KIA book as an early detection on growth and development of children under five is important. It aims to determine the characteristic and perception of mother with children under five about the use of KIA book. This study employed analytical correlational study with cross sectional approach. There were 124 respondents in Denpasar recruited as the samples of the study and were analyzed by using chi square test. The result of the study showed that most of the respondents were 26-30 years old (36.3\%), had one child (42.8\%), graduated from senior high school (52.4\%), and unemployed (33.1\%). Most of the respondents had positive perception (77.4\%) and most of them had good knowledge about the use of KIA book as an early detection on growth and development of children under five $(74,2 \%)$. There was a correlation between age $(p=0,075)$ and number of child $(p<0,001)$, education $(p=0,001)$ and perception $(p=0,02)$ toward the use of KIA book. Meanwhile, the occupation of mother did not correlate with the use of KIA book as an early detection on growth and development $(p=0,131)$. The mothers who have children under five are expected to use KIA bool well as an early detection on growth and development of children under five so they have healthy growth in the future.
\end{abstract}

Keywords : Children under five, KIA book, Early Detection, Growth and Development 


\section{PENDAHULUAN}

Pandemi COVID-19 yang melanda hampir di seluruh dunia termasuk Indonesia tidak akan bisa hilang dalam waktu cepat. Hal ini membuat pemerintah di Indonesia mulai memberlakukan aturan untuk diterapkan seluruh masyarakat yaitu masa adaptasi tatanan hipup baru. Tatanan hidup baru yang dimaksud yaitu perilaku hidup bersih dan sehat. Mulai dari selalu menggunakan masker saat keluar rumah, rajin mencuci tangan menggunakan sabun di air mengalir selama minimal 20 detik, menjaga jarak dan menghindari kerumunan (Kemenkes RI, 2020).

Tatanan hidup baru saat ini juga berdampak pada pelayanan kesehatan untuk balita terutama dalam hal pemantauan deteksi dini tumbuh kembang balita. Masa balita merupakan periode penting dalam tumbuh kembang anak, dimulai sejak berumur 12-59 bulan. Tahap ini, pertumbuhan dan perkembangan balita mulai dari motorik kasar, halus, bahasa dan sosialisasi mulai mengalami kemajuan yang pesat. Pertumbuhan dan perkembangan pada masa balita dapat mempengaruhi perkembangan selanjutnya. Oleh karena itu, penyimpangan pada pertumbuhan dan perkembangan anak jika tidak dideteksi dan di stimulasi dengan benar maka dapat mengganggu kualitas hidup anak di masa depan (Kemenkes RI, 2016).

Deteksi dini tumbuh kembang balita dapat dilakukan dengan cara melakukan pengkajian, pemeriksaan fisik, melakukan pemeriksaan pertumbuhan, dan skrining perkembangan. Deteksi dini tumbuh kembang pada balita dapat dipantau salah satunya dengan menggunakan Buku KIA (Kemenkes RI, 2016).

Pada tahun 2020, pemerintah melalui Kementerian Kesehatan Republik Indonesia telah merevisi buku Kesehatan Ibu dan Anak (KIA) dari tahun 2015. Buku KIA adalah buku catatan yang digunakan sebagai catatan kesehatan keluarga terutama ibu dan anak agar mendapatkan pelayanan kesehatan yang berkualitas dan dapat memelihara kesehatan secara optimal. Buku KIA berisi tentang informasi perawatan kesehatan ibu dan anak, catatan kesehatan ibu mulai dari kehamilan sampai masa nifas, catatan kelahiran bayi, jadwal imunisasi, pemberian vitamin A dan checklist tahap perkembangan anak sesuai usia yang dapat disi oleh orang tua atau petugas kesehatan (Dardjito, Sistiarani, Nurhayati, 2014).
Buku KIA dapat diperoleh di Puskesmas, posyandu, praktik mandiri bidan, polindes/poskesdes, rumah sakit dan rumah bersalin. Buku KIA diberikan kepada semua ibu hamil. Jika ibu hamil kembar, maka akan diberikan dua buku KIA. Buku $\mathrm{KIA}$ sangat mudah digunakan sebagai media edukasi karena lengkapnya informasi kesehatan untuk ibu dan anak hingga informasi kapan harus melakukan rujukan saat ibu dan anak mengalami komplikasi atau penyimpangan pertumbuhan dan perkembangan (Mintarsih, 2018).

Menurut Sulistiyaningsih (2019), persepsi ibu yang baik tentang manfaat buku $\mathrm{KIA}$ dapat berpengaruh terhadap pemanfaatan buku KIA yang optimal. Ibu yang memiliki balita dengan persepsi baik akan menggunakan buku KIA ntuk memantau pertumbuhan dan perkembangan anaknya, medeteksi dini perkembangan anak, dan memberikan stimulus perkembangan anak sesuai usia.

Hasil penelitian Sistiarani (2014), menunjukkan bahwa persepsi pencatatan pada buku KIA dapat meningkatkan pengetahuan ibu yang memiliki balita mengenai kesehatan tumbuh kembang balita. Kelengkapan pengisian Buku KIA mengenai deteksi dini tumbuh kembang balita dapat memberikan informasi dan edukasi pada ibu tentang status kesehatan balitanya sehingga dapat meningkatkan pengetahuan ibu.

Sejalan dengan hasil penelitian Rahmi dkk (2018), mengemukakan bahwa terdapat hubungan antara persepsi ibu dengan pemanfaatan buku KIA. Petugas kesehatan dan kader agar lebih mengoptimalkan penggunaan buku KIA mulai dari pencatatan, penyuluhan hingga komunikasi pada ibu yang memiliki balita sehingga memiliki persepsi yang baik terhadap pemanfaatan buku KIA bagi pertumbuhan dan perkembangan anak.

Studi pendahuluan yang telah dilakukan terhadap 20 orang ibu yang memiliki balita di Kota Denpasar ditemukan sebagian besar ibu yang memiliki balita telah menggunakan buku KIA dan memiliki persepsi yang baik terhadap pemanfaatan buku KIA. Namun, sebagian kecil ditemukan belum menggunakan buku KIA untuk mendeteksi gangguan tumbuh kembang balita. Sehingga peneliti tertarik untuk meneliti tentang karakteristik dan persepsi ibu balita tentang pemanfaatan buku kia 
sebagai deteksi dini tumbuh kembang balita di masa adaptasi tatanan hidup baru.

\section{METODE PENELITIAN}

Penelitian ini merupakan penelitian analitik korelasi dengan pendekatan cross sectional. Populasi pada penelitian ini adalah seluruh ibu yang mempunyai Balita di wilayah Denpasar. Jumlah sampel dalam penelitian ini 124 responden. Teknik sampling yang digunakan adalah consecutive sampling. Dalam penelitian ini sampel yang diambil adalah yang memenuhi kriteria inklusi yang telah ditetapkan oleh peneliti, yaitu: Ibu yang memiliki buku KIA, Ibu yang memiliki akses teknologi online, Ibu yang bisa membaca dan menulis, Ibu bersedia menjadi responden dan menandatangani inform consent.

Penelitian dilaksanakan pada bulan Juli sampai dengan September 2020. Tahap awal penelitian ini adalah ibu yang memiliki balita terlebih dahulu mengisi informed consent pada google formulir secara online. Kuesioner online menggunakan google formulir mencakup data karakteristik ibu yang mempunyai balita, Persepsi ibu tentang buku KIA dan pemanfaatan buku KIA sebagai deteksi dini tumbuh kembang balita. Pengisian google formulir memerlukan waktu sekitar 15 menit. Sebelum penelitian, ibu juga akan diinformasikan tata cara pengisian kuesioner online yang benar.

Analisis data dilakukan dengan uji Chi Square untuk mengetahui hubungan karakteristik dan persepsi dengan pemanfaatan buku KIA. Penelitian ini telah memperoleh keterangan Kelaikan Etik dengan Nomor 03.0048/KEPITEKESBALI/VII/2020 tertanggal 23 Juli 2020 dari Komisi Etik Fakultas Kesehatan Institut Teknologi dan Kesehatan Bali (ITEKES Bali).

\section{HASIL DAN PEMBAHASAN} HASIL

Karakteristik responden yang akan dijabarkan pada bagian ini meliputi umur ibu, jumlah anak, pekerjaan ibu dan Pendidikan ibu.

\begin{tabular}{lcc}
\multicolumn{3}{c}{ Tabel 1. Distribusi Frekuensi } \\
Karakteristik (n=124)
\end{tabular}

\begin{tabular}{lcc}
\hline 26-30 tahun & 45 & 36.3 \\
31-35 tahun & 36 & 29.0 \\
$\quad$ 35 tahun & 21 & 16.9 \\
\hline Jumlah anak & & \\
$\quad 1$ & 53 & 42.8 \\
\multicolumn{1}{c}{3} & 47 & 37.9 \\
$\quad 4$ & 20 & 16.1 \\
$\quad 5$ & 3 & 2.4 \\
$\quad 1$ & 0.8 \\
\hline Pekerjaan lbu & & \\
Tidak bekerja & 41 & 33.1 \\
PNS & 11 & 8.9 \\
Guru & 7 & 5.6 \\
Karyawan swasta & 38 & 30.6 \\
Pedagang & 16 & 12.9 \\
Wirausaha & 9 & 7.3 \\
Tenaga & 2 & 1.6 \\
kesehatan & & \\
\hline Pendidikan Ibu & & \\
Tidak sekolah & 1 & 0.8 \\
Pendidikan dasar & 6 & 4.8 \\
Pendidikan & 65 & 52.4 \\
menengah & & \\
Pendidikan Tinggi & 52 & 41.9 \\
\hline Total & 124 & 100.00 \\
\hline
\end{tabular}

Berdasarkan Tabel 1. Berdasarkan distribusi frekuensi karakteristik responden, sumber informasi serta tempat mendapatkan buku KIA di Denpasar didapatkan hasil bahwa responden paling banyak berumur 26-30 tahun (36.3\%), sebagian besar pendidikan terakhir responden yaitu Pendidikan menengah (SMA/SMK) sebanyak $52.4 \%$. sebanyak $33.1 \%$ responden tidak bekerja, hampir sama dengan jumlah yag bekerja sebagai pegawai swasta, yaitu $30.6 \%$. Sebagian responden memiliki 1 orang anak, yaitu $42.8 \%$.

\begin{tabular}{|c|c|c|}
\hline Variabel & $\mathbf{n}$ & $\%$ \\
\hline \multicolumn{3}{|l|}{ Pemanfaatan buku } \\
\hline KIA & 92 & 74.2 \\
\hline Baik & 31 & 25.0 \\
\hline Cukup & 1 & 0.8 \\
\hline \multicolumn{3}{|l|}{$\begin{array}{l}\text { Kurang } \\
\text { Persensi lbu }\end{array}$} \\
\hline Persepsi lbu & & \\
\hline Positif & 96 & 77.4 \\
\hline Negatif & 28 & 22.6 \\
\hline Total & 124 & 100.00 \\
\hline
\end{tabular}

Berdasarkan Tabel 2. Sebagian besar responden memiliki persepsi yang positif $(77,4 \%)$ serta mampu memanfaatkan buku 
KIA sebagai deteksi dini tumbuh kembang balita dengan baik $(74,2 \%)$

Tabel 3. Hubungan karakteristik dan Persepsi dengan Pemanfaatan buku KIA

\begin{tabular}{|c|c|c|c|c|}
\hline \multirow[t]{2}{*}{ Variabel } & \multicolumn{3}{|c|}{$\begin{array}{l}\text { Pemanfaatan Buku KIA sebagai } \\
\text { eteksi Dini Tumbuh Kembang }\end{array}$} & \multirow[t]{2}{*}{$\mathbf{p}$} \\
\hline & Baik (\%) & $\begin{array}{l}\text { Cukup } \\
\text { (\%) }\end{array}$ & $\begin{array}{l}\text { Kurang } \\
(\%)\end{array}$ & \\
\hline Persepsi & & & & \\
\hline Positif & $76(79.2)$ & $20(20.8)$ & 0 & 0.02 \\
\hline Negatif & $16(57.1)$ & $11(39.3)$ & $1(3.6)$ & \\
\hline \multicolumn{5}{|c|}{$\begin{array}{l}\text { Karakteristi } \\
\text { k responden }\end{array}$} \\
\hline Umur & & & & 0,07 \\
\hline$<26$ tahun & $16(72.7)$ & $6(27.3)$ & 0 & \\
\hline 26-30 tahun & $34(75.6)$ & $11(24.4)$ & 0 & \\
\hline 31-35 tahun & & & & \\
\hline$>35$ tahun & $31(86.1)$ & $5(13.9)$ & 0 & \\
\hline $\begin{array}{l}\text { Jumlah } \\
\text { anak } \\
1\end{array}$ & 11(52.4) & $9(42.9)$ & $1(4.8)$ & \\
\hline 2 & $41(77.4)$ & $12(22.6)$ & 0 & $<0,0$ \\
\hline 3 & $36(76.6)$ & $11(23.4)$ & 0 & 01 \\
\hline 4 & $13(65)$ & $7(35)$ & 0 & \\
\hline 5 & $2(66.7)$ & 0 & $1(33.3)$ & \\
\hline & 0 & $1(100)$ & & \\
\hline \multicolumn{5}{|l|}{$\begin{array}{l}\text { Pendidikan } \\
\text { terakhir }\end{array}$} \\
\hline $\begin{array}{l}\text { sekolah } \\
\text { Pendidikan }\end{array}$ & $1(100)$ & 0 & 0 & \\
\hline $\begin{array}{l}\text { Pendidikan } \\
\text { dasar } \\
\text { Pendidikan }\end{array}$ & $3(50)$ & $2(33.3)$ & $1(16,7)$ & 0,00 \\
\hline $\begin{array}{l}\text { Penalalkan } \\
\text { menengah } \\
\text { Pendidikan }\end{array}$ & $36(69.2)$ & $16(30.8)$ & 0 & \\
\hline Tinggi & $52(80)$ & $13(20)$ & 0 & \\
\hline \multicolumn{5}{|l|}{ Pekerjaan } \\
\hline $\begin{array}{l}\text { bekerja } \\
\text { PNS }\end{array}$ & $31(75.6)$ & $10(24.4)$ & 0 & \\
\hline Guru & $8(72.7)$ & $3(27.3)$ & 0 & \\
\hline Karyawan & $5(71.4)$ & $2(28.6)$ & 0 & \\
\hline $\begin{array}{l}\text { swasta } \\
\text { Pedagang }\end{array}$ & $31(81.6)$ & 7 (18.4) & 0 & \\
\hline Wirausaha & $9(56.2)$ & $7(43.8)$ & 0 & 0,13 \\
\hline Tenaga & $6(66.7)$ & $2(22.2)$ & 1(11.1) & 1 \\
\hline kesehatan & $2(100)$ & 0 & 0 & \\
\hline
\end{tabular}

Berdasarkan tabel 3. diatas bahwa ada hubungan antara persepsi ibu dengan pemanfaatan buku KIA sebagai deteksi dini pertumbuhan dan perkembangan dengan nilai 0,02 . Karakteristik umur, jumlah anak, pendidikan ibu berhubungan dengan pemanfaatan buku KIA, sedangkan karakteristik pekerjaan tidak berhubungan dengan pemanfaatan buku KIA.

\section{PEMBAHASAN}

Kesehatan Ibu dan Anak (KIA) adalah salah satu masalah utama dalam kesehatan keluarga. Kesehatan keluarga yang diutamakan adalah pencegahan terhadap penyakit dan gangguan dibandingkan pengobatan. Salah satu pencegahan yang dapat dilakukan dalam KIA adalah mencegah terjadianya gangguan perkembangan. Beberapa laporan menyebutkan gangguan perkembangan dalam hal ini keterlambatam motorik, autism, dan hiperaktif sering terjadi pada anak usia 0-6 tahun, dengan peningkatan kasus mencapai 8 persen. Sepuluh persen penduduk Indonesia adalah anak-anak dan balita, yang artinya lebih dari 20 juta penduduk Indonesia berisiko terjadinya gangguan perkembangan.

Pada beberapa negara lain, buku KIA telah diakui sebagai upaya untuk meningkatkan kualitas dan cakupan layanan KIA serta fitur penting dari aspek KIA layanan kesehatan primer. Tetapi masih banyak laporan menunjukkan bahwa terdapat penggunaan buku KIA yang tidak tepat oleh ibu atau pengasuh maupun pengukuran anak bawah lima tahun baik berat badan dan panjang badan oleh kader kesehatan. Berdasarkan data ini, sangat diperlukan untuk mengidentifikasi faktorfaktor yang berhubungan dengan penggunaan buku KIA di masyarakat.

Pada penelitian yang kami lakukan pada bulan Juli-September 2020 di kota Denpasar dengan melibatkan ibu dari anak balita yang memiliki buku KIA, sebanyak 124 ibu yang ikut dalam penelitian ini dengan usia ibu antara 20-39 tahun. Hampir sebagian besar ibu adalah ibu rumah tangga dan tidak bekerja. $52,4 \%$ responden berpendidikan menengah (SMA/SMK). $60,5 \%$ dari responden mendapatkan buku KIA dari praktik bidan yang didapatkan sejak kehamilan, dan $37.9 \%$ responden mendapatkan informasi tentang pemanfaatan buku KIA dari bidan. 
Faktor yang berhubungan dengan pemanfaatan buku KIA adalah Pendidikan terakhir ibu, jumlah anak dan usia ibu, sedangkan pekerjaan ibu tidak memiliki hubungan dengan pemanfaatan buku KIA. Terdapat perbedaan dengan Penelitian di Mongolia menunjukkan tidak ada perbedaan antara usia dalam membaca dan menulis dalam buku KIA begitu juga halnya penelitian yang dilaksanakan di Jepang juga menunjukkan bahwa lebih dari 98,3 persen peserta telah membaca buku pegangan, yang secara efektif dan tidak tergantung pada usia.

Pada kesehatan ibu dan anak, tingkat pendidikan ibu diketahui secara signifikan mempengaruhi akses dan pemanfaatan layanan kesehatan yang tersedia, sehingga didapatkan keuntungan yang terkait dengan kesehatan anak menjadi lebih baik. Penelitian ini menunjukkan bahwa pendidikan formal dan membaca literasi bukanlah jaminan untuk pemanfaatan informasi yang berbasis buku meskipun buku itu resmi dan berstandar nasional.

Penelitian ini juga menunjukkan bahwa pekerjaan ibu tidak mempengaruhi perhatian ibu terhadap pertumbuhan dan perkembangan anaknya, khususnya dalam bentuk pemanfaatan buku KIA, ibu yang bekerja di luar rumah sering dianggap memiliki perhatian yang kurang pada kesehatan anak yang disebabkan interaksi yang kurang antara ibu dan anak-anak mereka. Pemanfaatan buku KIA berhubungan dengan kunjungan ke Posyandu, hal ini karena Posyandu adalah kegiatan partisipasi masyarakat setempat dengan tenaga kesehatan untuk membantu ibu dan anak-anak mendapatkan akses yang mudah untuk perawatan kesehatan.

Persepsi adalah proses pengorganisasian, penginterpretasian terhadap rangsang yang diterima oleh organisme atau individu sehingga merupakan sesuatu yang berarti dan merupakan aktivitas yang intergrated dalam diri individu (Sunaryo, 2013). Persepsi ibu yang mempunyai balita tentang tentang pemanfaatan buku KIA sebagai Deteksi dini pertumbuhan dan perkembangan balita didapatkan $77,4 \%$ memiliki persepsi yang positif. Hal ini didukung oleh pernyataan bahwa sebagian besar $(99,2 \%)$ dari responden setuju dengan pernyataan bahwa isi dari buku KIA sangat bermanfaat bagi ibu dan keluarga karena mengandung informasi untuk kesehatan anak. Namun masih ada beberapa responden (33,7\%) yang menyatakan setuju bahwa informasi yang tercatat di buku KIA tidak mempengaruhi kesehatan anaknya. Ada beberapa responden $(22,8 \%)$ yang tidak setuju jika tulisan dan gambar yang terdapat di dalam buku KIA mudah dimengerti dan dipahami oleh ibu dan keluarga.

Hasil uji hubungan antara persepsi ibu tentang buku KIA dengan Pemanfaatan buku KIA sebagai deteksi dini tumbuh kembang balita dengan analisa uji statistik Chi Square didapatkan $p$ value 0,02 hal ini menunjukkan ada hubungan yang bermakna antara persepsi dengan pemanfaatan buku KIA sebagai deteksi dini pertumbuhan dan perkembangan balita. Hubungan ini didukung dari tabulasi silang antara persepsi ibu dengan pemanfaatan buku KIA sebagai deteksi dini pertumbuhan dan perkembangan balita yang menunjukkan adanya kecenderungan ibu yang mempunyai persepsi positif tentang buku KIA mampu memanfatkan dengan baik buku KIA sebagai deteksi dini tumbuh kembang balita jika dibandingkan dengan yang memiliki persepsi negatif. Menurut Walgito, proses terjadinya persepsi tergantung dari pengalaman masa lalu dan pendidikan yang diperoleh individu. Proses pembentukan persepsi sebagai pemaknaan hasil pengamatan yang diawali dengan adanya stimuli. Proses seleksi terjadi pada saat seseorang memperoleh informasi, maka akan berlangsung proses penyeleksian pesan tentang mana pesan yang dianggap penting dan tidak penting. sedangkan interpretasi berlangsung ketika yang bersangkutan memberi tafsiran atau makna terhadap informasi tersebut secara menyeluruh. Dalam teori ini terjadinya persepsi terbagi dalam beberapa tahapan. Tahap pertama, merupakan tahap yang 
dikenal dengan nama proses kealaman atau proses fisik, merupakan proses ditangkapnya suatu stimulus oleh alat indera manusia. Tahap kedua, merupakan tahap yang dikenal dengan proses fisiologis, merupakan proses diteruskannya stimulus yang diterima oleh reseptor (alat indera) melalui saraf-saraf sensoris. Tahap ketiga, merupakan tahap yang dikenal dengan nama proses psikologik, merupakan proses timbulnya kesadaran individu tentang stimulus yang diterima reseptor. Tahap ke empat, merupakan hasil yang diperoleh dari proses persepsi yaitu berupa tanggapan dan perilaku. Persepsi ibu tentang pemanfaatan buku KIA sebagai deteksi dini pertumbuhan dan perkembangan balita dapat diperoleh dari pengalaman, tingkat pendidikan, lingkungan sekitar, media elektronik maupun cetak dan sebagainya.

\section{KESIMPULAN}

Ada hubungan antara umur ibu, Pendidikan terakhir, jumlah anak dan persepsi dengan pemanfaatan buku KIA sebagai deteksi dini tumbuh kembang balita. Tidak ada hubungan pekerjaan ibu dengan pemanfaatan buku KIA sebagai deteksi dini tumbuh kembang balita.

\section{SARAN}

Petugas Kesehatan disarankan untuk mempertahankan mutu pelayanan yang ada dan selalu meningkatkan persepsi ibu tentang pemanfaatan buku KIA untuk mendeteksi secara dini pertumbuhan dan perkembagan balita serta melakukan stimulasi agar Kesehatan anak tetap optimal. Informasi hendaknya juga diberikan kepada suami atau keluarga lainnya sehingga dukungan keluarga bisa ditingkatkan.

Pemberian informasi oleh kader posyandu dapat ditingkatkan sehingga pemanfaatan buku KIA bisa dimaksimalkan oleh masyarakat dan informasi yang terdapat di dalam buku KIA dapat meningkatkan kesehatan ibu dan anak.

\section{DAFTAR PUSTAKA}

Adiningrum F, Sukandar H, Wijaya M. 2016. Hubungan Antara Pengetahuan lbu Tentang Buku Kia Dengan Status Gizi Anak Balita Di Kecamatan Soreang Kabupaten Bandung. Jsk.;2(2):7.

Dardjito E, Sistiarani C, Nurhayati S. 2014. Deteksi Pertumbuhan Dan Perkembangan Balita Melalui Penggunaan Buku Kia. Jurnal Kesmasindo. Vol.6(3):11.

Hasyim DI, Sulistianingsih, A. 2019. Pemanfaatan Informasi tentang Balita Usia 12-59 bulan pada Buku KIA dengan Kelengkapan Pencatatan Status Gizi di Buku KIA. Jurnal Kedokteran dam Kesehatan, vol 15, no 1.

Kalsum U, Febriyani. 2019. Faktor-faktor yang Berhubungan Dengan Pemanfaatan Buku KIA Terhadap Ibu Hamil di Wilayah Kerja Puskesmas Tigo Baleh Kota Bukittinggi tahun 2018. Maternal Child Health Care Journal, Vol 1, No 2: 63-75

Kementerian Kesehatan RI. 2020. Panduan Pelayanan Kesehatan Balita pada masa Pandemi Covid-19. Bagi Tenaga Kesehatan. Jakarta: Kemenkes RI

Kementerian Kesehatan RI. 2016. Pedoman pelaksanaan stimulasi, deteksi, dan intervensi dini tumbuh kembang anak. Jakarta: Kemenkes RI

Maharani K, Qomariyah, Rahimah N. 2019. Determinan Pemanfaatan Buku Kesehatan Ibu dan Anak (KIA) Pada Ibu Hamil Di Puskesmas Karangayu Kota Semarang. Jurnal Kesehatan STIKES Telogorejo, vol XI no 2, 69-75

Mariani. 2013. Faktor-Faktor Yang Berpengaruh Terhadap Pemanfaatan Buku Kesehatan Ibu Dan Anak Oleh Ibu Balita Di Desa Latong Kecamatan Seunagan Kabupaten Nagan Raya Tahun 2013. Aceh Barat: Universitas Teuku Umar

Mintarsih, Wiwin. 2018. Replikasi Kegiatan Pemanfaatan Buku KIA melalui Pendampingan Mahasiswa dan Kader 
Ni Wayan Manik Parwati, Idah Ayu Wulandari, Putu Ayu Ratna Darmayanti, Karateristik Dan Persepsi Ibu Balita Tentang Pemanfaatan Buku KIA Sebagai Deteksi Dini Tumbuh Kembang Balita Di Masa Adaptasi Tatanan Hidup Bru

Kesehatan. Jurnal Ilmiah Bidan. Vol.3(3):1- 10.

Mudany Ma, Sireng M, Rutherford Gw, Mwangi M, Nganga Lw, Gichangi,A. 2017. Enhancing Maternal And Child Health Using A Combined Mother \& Child Health Booklet In Kenya. J Trop Pediatr;61(6):7.

Paramitha, PAI. 2016. Faktor yang mempengaruhi pemanfaatan buku Kesehatan ibu dan anak (KIA) pada ibu Balita di Wilayah Kerja Puskesmas I Denpasar Timur. Universitas Udayana

Rahmi, Laila., Ika, Y.D., Silvi, Zaimy. 2018. Faktor-Faktor Yang Berhubungan Dengan Pemanfaatan Buku KIA. Jurnal IImu Kesehatan (JIK). Vol.2(1):68-74

Sandra, A. 2011. Hubungan Antara Pemanfaatan Buku Kia Dan Kepatuhan Imunisasi Di Puskesmas Ciputat Timur Kota Tangerang Selatan Depok: Universitas Indonesia

Sarasati Ra, Mawarni A, Dharmawan Y. 2016. Hubungan Beberapa Faktor Dengan Kelengkapan Pengisian Buku Kesehatan Ibu Dan Anak Oleh Bidan Desa Di Wilayah Kerja Puskesmas Jepara Tahun 2016. Jurnal Kesehatan Masyarakat.;4(4):8.

Sistiarani C, Gamelia E, Purnama Sari Du. 2014. Fungsi Pemanfaatan Buku Kia Terhadap Pengetahuan Kesehatan Ibu Dan Anak Dzul Istiqomah Hasyim, Apri Sulistianingsih. Pemanfaatan Informasi Tentang Balita Usia 12-59 Bulan Pada Buku KIA Dengan Kelengkapan Pencatatan Status Gizi Di Buku KIA Pada Ibu. Jurnal Kesehatan Masyarakat Nasional.;8(8):6.

Soetjiningsih. 2015. Tumbuh Kembang Anak. Jakarta: EGC

Sulistiyaningsih, Sri Hadi. 2019. Hubungan Pengetahuan dan Persepsi lbu Hamil dengan Pemanfaatan Buku KIA. Jurnal IImu Keperawatan dan Kebidanan. Vol.10(2);322-329

Therra Mt. 2012. Hubungan Pengetahuan Pemanfaatan Buku Kia Dengan Kemampuan Perawatan Balita Di
Posyandu Laras Lestari Nogotirto Yogyakarta. Yogyakarta: Stikes Aisyiyah Yogyakarta;.

Widagdo L, Husodo Bt. 2009. Pemanfaatan Buku Kia Oleh Kader Posyandu: Studi Pada Kader Posyandu Di Wilayah Kerja Puskesmas Kedungadem Kabupaten Bojonegoro. Makara, Kesehatan.;13(1):9.

Wijhati Er, Suryantoro P, Rokhanawati D. 2017. Optimalisasi Peran Kader Dalam Pemanfaatan Buku Kia Di Puskesmas Tegalrejo Kota Yogyakarta. Jurnal Kebidanan,.;6(2):8. 